\title{
A General Analysis of Lu Xun's Short Stories
}

\author{
GUO Yu \\ Leshan Normal University, Sichuan, China
}

\begin{abstract}
Father of modern Chinese literature, $\mathrm{Lu}$ Xun, is the first writer to use the vernacular to write fiction. In his short stories, he exposes the crimes of feudalism and describes the plight of the peasants, who have been economically exploited and spiritually enslaved. He also depicts the fate of the intellectuals who struggle in the intense social contradictions. His fiction has laid a solid foundation for the development of modern Chinese fiction. Lu Xun has created almost all the new forms for Chinese new literature, and enjoys the most prominent status in the Chinese literary development in the 20th century. His writings reflect the great achievements of the literary reform since the May Fourth Movement.
\end{abstract}

Keywords: Lu Xun's short stories, modern Chinese literature, theme, structure, style, achievements

\section{Introduction}

Lu Xun (1881-1936) has been acclaimed Father of modern Chinese literature. He is the first writer to use the vernacular to write fiction. His stories have laid a solid foundation for the development of modern Chinese fiction. Call to Arms (1923) and Wandering (1926) represent the greatest achievement of Chinese story-writing at that time. His short stories are not only profound in thinking, but also worthy of admiration for their great value and innovation in art. Since 1920's, Lu Xun's stories have been translated into various languages and published throughout the world, enjoying an international reputation. It is the central theme of his stories to fiercely attack and criticize the negative parts of Chinese culture, ethics, and traditions in the feudal society with a history of more than 2,000 years. At the same time, they also discuss and reflect the problems concerning the 1911 Revolution, Chinese peasants, including women, as well as intellectuals. In addition to the content, Lu Xun also reforms, in an artistic way, the traditional way of Chinese fiction writing. Moreover, with the prerequisite of "writing for the sake of human life", Lu Xun has formed his unique aesthetic characteristic with a perfect combination of realism, romanticism, and symbolism. The last but not the least, there are abundant culture-bound images in his stories, including Chinese traditional thought and customs, which play a significant role in cross-cultural communication nowadays.

\section{Theme}

It is $\mathrm{Lu}$ Xun who begins to explore the two main themes-peasants and intellectuals-for modern Chinese stories, and for the first time really writes about common people in daily life. He is so much concerned about not only physical but also spiritual sufferings and harmfulness imposed upon Chinese people that he brings about the issue of "removing national characteristics" and "transforming the Chinese psyche" by means of writing stories.

GUO Yu, master, lecturer, School of Foreign Languages, Leshan Normal University, Sichuan, China. 
No writer before Lu Xun has shown the same feeling of equality in the portrayal of the peasants. Neither is there a single piece of writing about the peasants which fundamentally negates the feudal system as Lu Xun has done, presenting the reader at the same time with a wide and perceptive historical view. (Tang, 1993, p. 100)

His stories well portray the complex class relationships in the peasant community in China's society at that time. He writes about the physical sufferings of the peasants resulted from economic exploitation and exposes the root causes of their miserable lives. Significantly, he has given prime attention to their mentality after they have been long poisoned by feudal ideas. Ah $\mathrm{Q}$ is such a typical peasant of this kind, one who has been seriously harmed both mentally and materially. In addition, Runtu is an unforgettable and pathetic person who suffered much from hard work and sub-marginal living. Lu Xun's deep concern also goes to the intellectuals. The stories "In the Wineshop" and "The Misanthrope" describe the conflict between expectations and the reality, the clash between the force of revolution and the force of customs. In the former story, Lü Weifu, originally an extremely capable and energetic young man, became to feel disappointed about the reality, attend to "trivial matters", and live a life of this kind: like a fly which "would come back again to stop in the same place after making a small circle" (H. Y. Yang \& G. Yang, 1960, p. 193). In the latter story, Wei Lianshu has a more gloomy outlook and is uncaring. He drifts from anxiety and restlessness to dejection and decadence till death. In "Regret for the Past", the author describes in poetic language Juansheng's state of mind, and Lu Xun's criticism is contained in the detailed narration of events. What is more, he does more than showing sympathy to the intellectuals. Instead, he is always trying to give an analysis of the root of the conflict between the individual and the society. He usually adds some light of hope into the gloomy and desperate reality. Therefore, "sparkling in Lu Xun's works are the ideals which inspire people to move forward", and which "are the indispensable elements of his realism in his exposure of the corrupt society" (Tang, 1993, p. 102).

\section{Artistic Features}

Lu Xun's stories are the monument of China at that time. Varied in forms, the stories draw on a mixture of influences, both Chinese and foreign, which is manifested in their unique artistic features. Firstly, his stories are full of originality and written in a most distinctive style. "Rich but not gaudy, it flows smoothly and carries profound thoughts, blending humour with seriousness" (Tang, 1993, p. 102). With the purpose to "expose the disease and draw attention to it so that it might be cured" (H. Y. Yang \& G. Yang, 1980, p. 263), he tries every means to examine and attack feudal ethics, culture, and ruling system in China. He is profound to the greatest extent for he has pointed out that the nature of feudal ethics is man-eating, which constitutes to be fought against fiercely and powerfully over and over again by the author in most of his stories. He says it is essential to choose materials strictly before writing and try to explore them as deeply as possible when writing.

Secondly, his works look very calm and emotionless on the surface, but on the contrary, they are full of his deep and strong feelings, love or hate, sympathy or isolation. For instance, he has never directly wrote much about death, one of the most frequent scenes in his stories, instead, he always tried to lead readers to the society in which death inevitably and repeatedly happens, stimulating readers' strong indignation and deep self-examination. 
Thirdly, Lu Xun's stories are especially famous and attractive for his concise style. He once said:

I did my best to avoid all wordiness. If I felt I had made my meaning sufficiently clear, I was glad to dispense with frills. The old Chinese theatre has no scenery, and the New Year pictures sold to children show a few figures only. Convinced that such methods suited my purpose, I did not indulge in irrelevant details and kept the dialogue down to a minimum (H. Y. Yang \& G. Yang, 1980, p. 263).

It is obvious that he uses as few words as possible to make a comprehensive sketch of a character's features, mentality, and so on. He said, "You must sketch a man's features with a minimum of strokes, the best way is to draw his eyes" (H. Y. Yang \& G. Yang, 1980, p. 263). This remarkable technique is evident in "Kong Yiji", "Medicine", and "Storm in a Teacup". A good example in point is his description of natural scenery and social surroundings, which are always embodied with profound cultural messages and rich emotions just like those in Chinese classical poetry. Lu Xun is a master of short stories for he excels in specifying his thoughts naturally and evidently, showing great events by small episodes and depicting typical characters by only a few ordinary people. "Lu Xun's technique of 'drawing the eyes' and 'catching the soul' of a character is highly effective. It strengthens the affective power of art, touching not only the reader's heart but also his very soul" (Tang, 1993, p. 103). His language is featured for its naturalness, freshness, and vividness. Besides, his language is humorous and full of feelings and philosophical thinking, especially shown in "My Old Home", "Village Opera", "The Misanthrope", and "Regret for the Past".

Fourthly, Lu Xun has conceived and managed his settings in quite a plain way. He does no directly write serious events for the sake of its own, instead, he just writes about common people's small incidents in daily life to reflect their life and fate in such an era. In another word, his stories are not to reflect some historical events themselves but to show how and why changes happen to those peasants and intellectuals. If he is concerned with the fate of the "nobody", this man is a peasant like his childhood friend Runtu whom hard work and sub-marginal living has made into a pathetic creature of a former cheerful, vivacious teenager. Also, readers may feel how ruthless and cold the society is through the despair and isolation of Xianglin's wife and Mrs. Shan. In Lu Xun's writing, these characters' fate is just a mirror to reflect that historical period.

Fifthly, Lu Xun's stories are characterized with sense of humor and satirical irony. The nature of comedy in his stories, above all, is his attitude of "sorrow for their misfortune while anger about their nonresistance" toward people's unawakened spirit. Hence, his humor is by no means some joyful and relaxing jokes, on the contrary, it is serious and heavy under the peaceful and ridiculous surface, for humor of his kind is never to make people laugh. Take for instance "The True Story of Ah Q". Every time after having been beaten, Ah Q would try to make he himself treat it in another way, that is, "spiritual victory". The more one reads, the sadder and more indignant he is. Lu Xun's stories usually make people smile with tears by a combination of joy and sorrow, comedy and tragedy. Besides, his skill of irony best exhibits in three ironical stories "Soap", "Master Gao", and "Brothers". In a word, Lu Xun's realism is "of a much higher order" and "his works are unequalled in freshness, depth and clarity" (Tang, 1993, p. 105).

\section{Structure}

How to construct and manage settings and scenes is an important artistic way to display content and expose theme, in particular, in short stories. Lu Xun is such a master who has three principles in structure. Above all, structure serves theme. A good example in point is "Medicine", in which there are two clues, one is Old Shuan, and the other is Xia Yu, the revolutionary. They are connected with each other by the "steam bread 
made with human's blood". In describing the unawakened mental state of the people, which makes the writer indignant and distressed, Lu Xun is here recalling his experiences in Japan, when the teacher showed films of the Russo-Japanese War. At the end of the story, the image of the crow has been regarded as "being evidently retains the Andreyev-type gloom" (Xia, 2005, p. 27). In addition, there also appears a wreath at Xia Yu's grave so as to hold out "some rays of hope" (H. Y. Yang \& G. Yang, 1980, p. 201). Perhaps he had the revolutionary Qiu Jin in mind at that time, for she must have been the original of Xia Yu (Zhou, 2002).

Secondly, structure is decided by protagonists' personalities. To sum up, there are two types of structures in Lu Xun's stories. One is greatly influenced by Western style, that is, the author describes characters' movements and actions only at specific time, in specific scenes and against specific background. For example, "Tomorrow" is about the death of a child due to a doctor's weird prescription, in which the author refuses to exaggerate the tragic atmosphere. Instead of describing the grief of fourth Shan's wife at her son's death, the writer devotes more space to exposing the root of evil in the old society and drawing attention to it so that some cure might be found. In the final analysis, however, we shall not simply ascribe the misfortune of fourth Shan's wife to the criminal acts of a certain individuals, but should denounce the society that gave rise to such misfortune. The other type has inherited the style of traditional Chinese stories to greater extent, namely, the stories are mainly narrative, merging with descriptions of scenes, in which figures' lives have been extended in both time and space. Within the limits of short stories, only several representative episodes are contained to reveal figures' fate. A case in point is "Kong Yiji". The author, though sympathetic towards the miserable man, places no hopes on him, but takes a critical approach to him. Lu Xun observes and describes the progressive decay of the human wreck within less than 3,000 Chinese characters. Thanks to his artistic generalization, this artistic image, a worried look on his scarred face, continued to appear in our mind's eye from time to time.

Thirdly, by the principle of diversification combined with unification, structure is used to give prominence to theme by means of sharp contrast and opposition. For instance, "An Incident", written in an entirely different way and highly lyrical, has made a contrast first between the beautiful "incident" and those ugly "national events", then between the uprightness and goodness of the rickshaw, the working class, and the hesitation and skepticism of "me", the bourgeois. It must be pointed out that, in the new literary history of modern China, a new and highly significant theme made its first appearance here-the theme of the ideological remolding of bourgeois and petty bourgeois intellectuals, which was later repeated many times in Lu Xun's other stories. This is one of the great writer's outstanding contributions to modern China's new literature. It is also one salient aspect where he towers high above writers of his own time.

\section{National Style}

$\mathrm{Lu}$ Xun is talented for carrying forward the fine national traditions. Moreover, his short stories not only get rid of traditional spiritual barriers and "expose the disease and draw attention to it so that it might be cured", but also give up the traditional happy-ending pattern and replace it with tragedy structure and comedy atmosphere. In a word, his stories create a kind of brand-new national style with the combination of excellent traditional classics and what is best in foreign literature.

Firstly, from the perspective of content, Lu Xun's stories provide us with a unique and vivid picture of countryside and little towns in Jiang Nan (the area within the southern of Yangtze River). In fact, the typical surroundings and scenery which he most often describes as well as most of the typical characters and events he depicts are invariably derived from the countryside of his native place, Shaoxing. It is true that culture is highly 
condensed in and manifested by folk customs. Lu Xun was, through his description of those folk customs in Zhejiang Province, trying to expose the sickness and laziness of Chinese national characters, such as numbness, blindness, and cannibalism, and then to attack on the feudal ethics.

Secondly, only through perfect form can content be well represented. So do Lu Xun's stories, which retain the national style not only in content but also in forms, in particular, language. First of all, his language is characterized by contemporary people's oral language and some dialects, trenchantly and vividly. Such as, “曲 曲折折的汇出手来” (Zhang, 2005, p. 148); “这死尸自作自受! ……现在弄得僧不僧道不道的” (Zhang, 2005, p. 42); besides, the author uses some archaic words to add his national features. He once said, "I'd rather refer to archaic words if there's no appropriate vernacular counterparts to make it clear to readers; I'll never use those characters and sentences only understandable to myself or even not" (H. Y. Yang \& G. Yang, 1980, p. 263). His purpose is to use archaism naturally and harmoniously so as to express himself properly and effectively. For instance, “塞翁失马安之非福” is used to describe Ah Q's fate in the gambling game. He also puts some archaic words into his own words, for example, “不到两个时辰, 我的意兴早已索然, 颇悔此来 为多事了” (H. Y. Yang \& G. Yang, 1980, p. 134). Meanwhile, he is firmly opposed to use archaic words unnecessarily and randomly, for his own usage of archaism is just like what Li Yu (李渔, 1611-1680) said, “妙 在信手拈来, 无心巧合, 竟似古人寻我, 并非我受古人”1.

Thirdly, Lu Xun has inherited the "line drawing" method in Chinese classic stories. Therefore, he always emphasizes portraying their inner characters while only drawing the outline of their appearances and images. A good example in point is the portrait of the world-famous Ah Q with a few words: “这时阿Q赤着膊, 懒洋洋 的瘦伶仃的……最恼人的是在他头皮上, 颇有几处不知起于何时的癞疮疮” (Zhang, 2005, pp. 57-58). Such description of appearance is for the purpose of manifesting Ah Q's personal character-“spiritual victory". Another feature of this kind of "line drawing" is trying to depict personalities through people's activities and dialogues instead of slack analyses and simple psychological descriptions. Sometimes, Lu Xun does not write anything about appearance at all and completely relies on dialogues, such as the Greybeard in "Medicine" and He Daotong in "Soap". Certainly, his description of dialogues is precise, in accordance with his principle of "drawing one's eyes".

What is more, the writer has made a close integration of environmental depiction and personality description, assimilating advantages of traditional Chinese art. He has never exaggerated the function of surroundings, but he has tried to work a typical environment not invisible but sensible through the atmosphere formed by people's activities. For example, in "Village Opera", he writes about pleasure and naivete of little kids rather than pure beautiful scenery at night in Shaoxing; in "The New Year's Sacrifice", he depicts the joyful and happy scene on the New Year's Eve to set off in contrast the tragic fate of Xiangling's wife.

\section{Great Achievements and Influence}

As soon as it appeared, "A Madman's Diary" has aroused great attention both at home and abroad. A Japanese writer once said that $\mathrm{Lu}$ Xun is a writer who belongs to the future in the field of fiction. ... "A Madman's Diary" has achieved such a state that his counterparts are left far behind and cannot even catch up with him (Yan, 2002, p. 80). In this way, Lu Xun is a very artistically mature storywriter since his debut in the literary world and his stories have shortened the time of establishment of China's modern fiction. Call to Arms

${ }^{1}$ See (清) 李渔, 《闲情偶寄・词采第二・贵显浅》。 
and Wandering have initiated realism and set a good example for modern Chinese literature on account of their great achievements and innovation both spiritually and artistically.

Above all, Lu Xun writes his stories with brilliant originality in both content and forms. Firstly, he uses for the first time the elaborate psychological descriptions and self analyses. Secondly, in his stories appear, for the first time, various narrative angles of modern fiction. Half of his stories in Call to Arms and Wandering are written in the first person. In other stories, he has either combined the first-person narration with the third-person description, or written in the first person by different means. Compared with the singularity of narration of classical fiction, it is no doubt amazing and admirable. Thirdly, there are tremendous changes of delineation in his stories of not only characters but also surroundings and scenery. Fourthly, in the development of China's comedy aesthetics, his stories provide for the first time with a new principle of comedy. In fact, his stories are full of pungent irony instead of relaxed humor, for there is always a sharp contrast between the ideal wonderful life recognized by the traditional society and the current reality of China. Fifthly, Lu Xun's stories are the very beginning of complete tragic works of China, in which sorrow and grief can never be weakened and eased. What is more, the writer prefers to one's spiritual value rather than physical life so that he has never omitted in his stories that how one is destroyed in spirit. In a word, his writing of tragedy is unique and incomparable.

Secondly, from the aspect of spiritual and cultural value, Lu Xun has criticized the "man-eating" nature of feudal despotism in his stories, which has never been concerned before. He has emphasized especially on the spiritual enslavement and harm imposed upon people by feudal despotism and ethical code, hence advocated "altering national deficiencies and low qualities". And through his concern about issues of peasants and intellectuals, he has displayed his caring for fate of lower-class people, along with his humanism. The last but not the least, he has disclosed the evilness of human nature and criticized feudal culture to some unprecedented extent.

Thirdly, from the point of view of artistic value, Lu Xun has explored and enriched techniques of modern Chinese fiction, and provided so many classics in full sense:

(1) His artistic styles are diversified, for he prefers to "line drawing" as a whole, yet he still has excellent lyrical stories, ironic stories, and native-country stories.

(2) He has broken traditional Chinese fiction's single structure and happy ending, and experimented various forms including diary, handwritten notes, writing composed of chapters, and essays. Just as Mao Dun (茅盾, 1896-1981) said in his “On Reading Call to Arms".

In China's new world of letters, Lu Xunhas always been a pioneer in creating new forms. ... Almost each has a distinctive new form of its own. All these new forms are bound to exert a tremendous influence upon young writers ... What else have we got to say about Lu Hsun's works except our appreciation and admiration? ${ }^{2}$

(3) Lu Xun has molded a series of vivid and unforgettable characters in his stories which deeply impressed readers of different times.

(4) He has initiated and practiced vernacular in writing and his language is connotative, reserved, and concise, for in talking about his own writing habits, he once gave this advice: "Read your story through at least twice after finishing it, and ruthlessly cut all words, phrases and sections that are not essential" (Wang, 1984, p. 311).

${ }^{2}$ See Literature Weekly, No. 91, October 8, 1922. 
The Japanese writer Shikaji once paid tribute to Lu Xun in the most fervent terms:

His footprints are the footprints of the growth of new China. In the whole realm of culture... when one wants to investigate the growth of the new age, he finds Lu Xun everywhere. His name is the symbol of new China. (Weiss, 1985, p. 209)

Edgar Snow has recognized Lu Xun as "one of the few writers like Gorky in Russia, Voltaire in the French Revolution and Romain Rolland today who have been an integral part of the history of nations", and compared him with Voltaire "because he was the most powerful fighter in China against feudalism" (Weiss, 1985, p. 211). The Russian writer A. A. Fadeyev compared Lu Xun with Chekhov and Gorky for "no aspect of the contemporary life of the Chinese people escaped his pen, either artistically or critically" (Weiss, 1985, p. 237). Undoubtedly, on no accounts should the great historical significance of Lu Xun's stories be underestimated. He is, then, "very much a product of China, a China chastened and ennobled by the intensified sufferings that she has gone through during the past fifty or more years and is still going through". And also, "he is the first one to diagnose the fundamental flaw in the Chinese character, the first one to see the Ah Q in us, the first one to make us see the Ah Q in ourselves" (Wang, 1939, p. 99).

\section{Conclusion}

As a whole, the evaluation of $\mathrm{Lu}$ Xun and his stories has undergone great changes since his death. The writer himself was, at the beginning, acclaimed "national hero" in Chinese mainland, holding unprecedented supreme status as apotheosis. In the meantime, he was smeared and all of his works were banned in Taiwan. Then, Lu Xun and his works, especially his stories, were criticized and attacked by some scholars in 1990's in Chinese mainland, for they hold that $\mathrm{Lu}$ Xun has never written any novel, while he was highly praised in Taiwan at the same time. However, recent years have seen a tendency of trying to objectively and fairly evaluate the author as well as his works. All of these changes have made impact upon Western readers through various translations of Lu Xun's stories at different times. To sum up, Lu Xun is neither an apotheosis, nor a writer more in name than in reality. In fact, he is really modern China's foremost writer and intellectual (Lee, 1985).

In conclusion, modern Chinese fiction has begun with Lu Xun's stories and still become mature with them, which is very uncommon in history. Maybe Lu Xun's own words can clarify his stories and the reason why he chose literature instead of medicine as his career in all his life:

As to why I wrote, I still felt, as I has a dozen years earlier, that I should write in the hope of enlightening people, for humanity, and of the need to better it. I detested the old habit of describing fiction as "entertainment", and regarded "art for art's sake" as simply another name for passing the time. So my themes were usually the unfortunates in this abnormal society. My aim was to expose the disease and draw attention to it so that it might be cured (H. Y. Yang \& G. Yang, 1980, p. 263).

\section{References}

Cao, J. R. (2006). A critical bibliography of Lu Xun. Shanghai: Fudan University Press.

Hsia, T. A. (2004). The gate of darkness: Studies on the Leftist Literary Movement in China. Seattle: University of Washington Press.

Lee, L. O. (Ed.). (1985). Lu Xun and his legacy. Berkeley: University of California Press.

Lee, L. O. (Ed.). (1987). Voices from the iron house: A study of Lu Xun. Bloomington: Indiana University Press. 
Lu, Y. D., \& Tang, D. H. (1984). The first exploration on the originality of Lu Xun's stories. Changsha: Hunan People's Publishing House.

Lyell, W. A. (Trans.). (1990). Diary of a madman and other stories. Honolulu: University of Hawaii Press.

Qian, L. Q. (2003). A general analysis of Lu Xun's work. Beijing: Peking University Press.

Peng, B. (2001). The comparative structure of desperation and hope in Lu Xun's stories. Shanghai: Academia Press.

Shen, D. (1998). Literary stylistics and fictional translation. Beijing: Peking University Press.

Shen, D. (2001). Narratology and the stylistics of fiction. Beijing: Peking University Press.

Tang, T. (1993). History of modern Chinese literature. Beijing: Foreign Languages Press.

Wang, C. C. (1939). Lusin: A chronological record, 1881-1936. China Institute Bulletin, 3(4), 99-105.

Wang, C. C. (Trans.). (1941). Ah Q and others: Selected stories of Lusin. New York: Columbia University Press.

Wang, S. J. (1984). Lu Xun: A biography. Beijing: Foreign Languages Press.

Weiss, R. F. (1985). Lu Xun-A Chinese writer for all times. Beijing: New World Press.

Xia, Z. Q. (2005). A history of modern Chinese fiction. Shanghai: Fudan University Press.

Yang, H. Y., \& Yang, G. (Trans.). (1954). Selected stories of Lu Hsun. Peking: Foreign Languages Press.

Yang, H. Y., \& Yang, G. (Trans.). (1960). Selected stories of Lu Hsun. Peking: Foreign Languages Press.

Yang, H. Y., \& Yang, G. (Trans.). (1972). Selected stories of Lu Hsun. Peking: Foreign Languages Press.

Yang, H. Y., \& Yang, G. (Trans.). (1980). Selected works of Lu Xun. Peking: Foreign Languages Press.

Yan, J. Y. (2002). On Lu Xun's polyphonic fiction. Shanghai: Shanghai Educational Publishing House.

Zhang, X. F. (Ed.). (2005). A new edition of Lu Xun's stories. Beijing: Beijing University of Technology Press.

Zhou, Z. R. (2002). Characters in Lu Xun's sories. Shijiazhuang: Hebei Educational Publishing House. 